\title{
Modeling and Simulation of 1000MW Double Reheat Ultra-supercritical Unit based on Particle Swarm Optimization
}

\author{
Lixin Chen ${ }^{1}$, Xueping Zhou, Hao Zhao \\ Datang Huayin Youxian Energy Corporation Limited, Zhuzhou, 412300, China \\ 1email: 873634790@qq.com
}

\begin{abstract}
Keywords: Simulation System; 1000MW Double Reheat Ultra-supercritical Unit; Steam Temperature; Particle Swarm Optimization
\end{abstract}

\begin{abstract}
The steam temperature dynamics was researched under the simulation system of 1000MW double reheat ultra-supercritical unit, the steam temperature response curves under various disturbances were obtained. The transfer function model of the main steam temperature, the first reheat steam temperature and the second reheat steam temperature under various disturbances was identified based on the algorithm of Particle Swarm Optimization (PSO). The steam temperature system model of double reheat ultra-supercritical unit was built in the Matlab/simulink platform, a simulation study was carried out. Results show that the simulation model is consistent with the actual model, and can be applied in the dynamics research or control system design of the steam temperature system in double reheat ultra-supercritical unit.
\end{abstract}

\section{Introduction}

Double reheat unit has more a level reheater compared to the conventional reheat unit, the boiler heating surface distribution is more complicated, and more factors can affect the steam temperature. It is the emphasis and difficulty of designing the steam temperature control system in double reheat unit how to well control the main steam temperature, the first reheat steam temperature and the second reheat steam temperature. A model that can well reflect the steam temperature system features has important value for designing and researching the steam temperature control system in double reheat unit. How to acquire a more accurate mathematical model of double-reheat unit is the key to the steam temperature system modeling and control.

Particle Swarm Optimization (PSO) is a kind of swarm intelligence calculation method imitating the flock foraging behavior, put forward in 1995 by James Kennedy and Russell Eberhart [1]. The basic idea is a process of finding the optimal solution within a certain range by calculating fitness of the particle in the space relative to the objective function, making the particle group collaboration, and sharing information. The advantage of this algorithm is simple code, less adjustable parameters, and ease of implementation. It is now widely used in parameter optimization [2], system identification [3], training neural networks [4], fuzzy systems control [5] and other control fields.

This paper acquired the test data by simulation system, and then identified the each channel transfer function of the steam temperature system in double reheat ultra-supercritical unit, finally established the model of the steam temperature system for designing and validating the steam temperature control system in MATLAB/Simulink platform.

\section{Analysis of double reheat ultra-supercritical steam temperature system}

The steam temperature control system discussed in this paper has three controlled objects, they are the superheater, the first reheater, and the second reheater. The superheated steam temperature is mainly affected by water-coal ratio and desuperheating water, and also influenced by tilting angle of burner. In actual control system, water-coal ratio is adjusted by intermediate point temperature, while desuperheating water is adjusted based on the superheater outlet temperature. The main factors affecting the first and the second reheat steam temperature are water-coal ratio, flue gas damper, tilting angle of burner and desuperheating water, the influence of water-coal ratio is mainly 
affected by the change of the superheated steam temperature. In actual control system, the tilting angle of burner is used to adjust the overall average of the first and the second reheat steam temperature, the flue gas damper is to adjust the deviation of them, and the desuperheating water is to adjust each levels reheater outlet temperature. Through theoretical analysis of the steam temperature system, the relationship between input and output is shown in Figure 1.

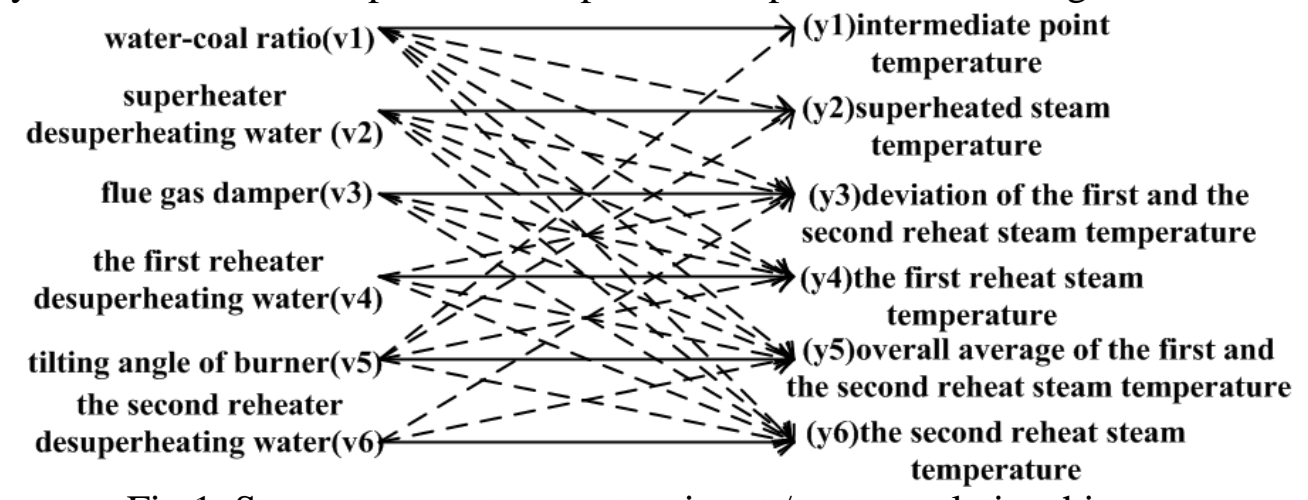

Fig.1. Steam temperature system input / output relationship

As shown in Figure 1, the solid arrow represents that output is affected by input directly, while the dashed arrow indicates that input affects indirectly output. The steam temperature system has 6 inputs, 6 outputs, and complex coupling relationship between input and output, but it is just theoretical analysis, an input may lead to other outputs change in the actual system, so the system becomes more complex. In order to acquire the transfer function between input and output, make experiments in the simulation system and complete the data collection, and then the system transfer function is obtained by identification with the experiment data.

\section{Modeling on double reheat ultra-supercritical steam temperature system}

This paper carried out 6 experiments under 88\% load by adopting the 1000MW double reheat simulation system GD taizhou, which is to obtain the effects that 6 inputs of the steam temperature system affect respectively 6 outputs. The simulation system has the following parameters: initial condition is turbine follow (TF), active power $880 \mathrm{MW}$, the main steam pressure and temperature, $28.88 \mathrm{MPa}, 591.5^{\circ} \mathrm{C}$, the first reheat steam pressure and temperature, $9.69 \mathrm{MPa}, 588.3^{\circ} \mathrm{C}$, the second reheat steam pressure and temperature, $2.87 \mathrm{MPa}, 596.9^{\circ} \mathrm{C}$, feed water flow $2224 \mathrm{t} / \mathrm{h}$, total coal $340.5 \mathrm{t} / \mathrm{h}$, water-coal ratio 6.8 , and all desuperheating water valve with manual operation. To obtain the influence that an input has on six outputs, other inputs must be the same in experiment.

Experiment data are used to identify the transfer function based on PSO, the algorithm has the following parameters: the particle number 50, the maximum number of iteration 80 , forgetting factor 0.4 , learning factor $c_{1}=0.6, c_{2}=0.6$. The transfer function is denoted as $G_{\mathrm{mn}}(s)$ between the input $v_{\mathrm{m}}$ and the output $y_{\mathrm{n}}$ shown in Figure 1 , where $m=1,2, \ldots, 6 ; n=1,2, \ldots, 6$.

Experiment 1 looks at how water-coal ratio affects steam temperature. DCS reheat system adopts water-coal ratio to regulate the intermediate point temperature that is the outlet temperature of steam-water separator. Water-coal ratio can be changed by the economizer inlet flow because of the experiment condition with TF mode, fuel control and all desuperheating water valve with manual operation. In the case of other conditions unchanged, the economizer inlet flow increases by $100 \mathrm{t} / \mathrm{h}$, each of the steam temperature response is obtained as shown in Figure 2.

The transfer function is acquired between water-coal ratio $\left(v_{1}\right)$ and intermediate point temperature $\left(y_{1}\right)$, superheated steam temperature $\left(y_{2}\right)$, the first reheat steam temperature $\left(y_{4}\right)$, the second reheat steam temperature $\left(y_{6}\right)$ as follows:

$$
\begin{aligned}
& G_{11}(s)=\frac{17.7373}{(32.7 s+1)^{2}}-\frac{22.91}{(9.2 s+1)^{2}}, G_{12}(s)=\frac{-85.3265}{(277.0471 s+1)^{2}} \\
& G_{14}(s)=\frac{-70.0854}{(208.8058 s+1)^{2}}, G_{16}(s)=\frac{-66.5154}{(147.5705 s+1)^{2}}
\end{aligned}
$$


Experiment 2 looks at how the second superheater desuperheating water valve affects steam temperature. Two stage water spray is adopted by this unit, the temperature is affected more obviously by the second desuperheating water due to it is closest to the superheater outlet. The second superheater desuperheating water valve is increased from $50 \%$ to $80 \%$ in the case of other conditions unchanged, the response of the steam temperature is obtained as shown in Figure 3.

The transfer function is acquired between the second superheater desuperheating water valve $\left(v_{2}\right)$ and superheated steam temperature $\left(y_{2}\right)$, the first reheat steam temperature $\left(y_{4}\right)$, the second reheat steam temperature $\left(y_{6}\right)$ as follows:

$$
\begin{aligned}
G_{22}(s) & =\frac{-0.1892}{(27.2868 s+1)^{2}}, G_{24}(s)=\frac{-0.0323}{(67.2192 s+1)^{2}} \\
G_{26}(s) & =\frac{-0.0268}{120.7844 s+1}
\end{aligned}
$$

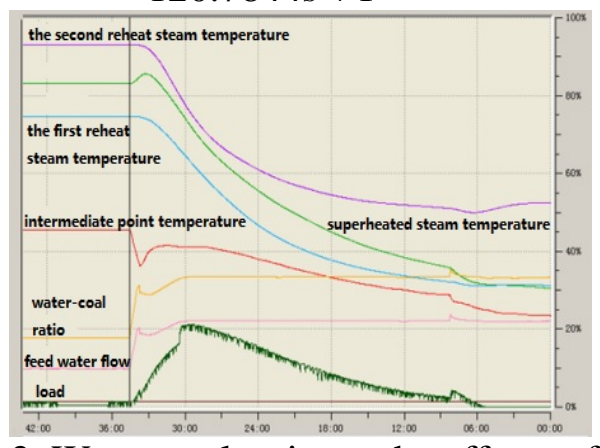

Fig.2. Water-coal ratio on the effects of steam temperature

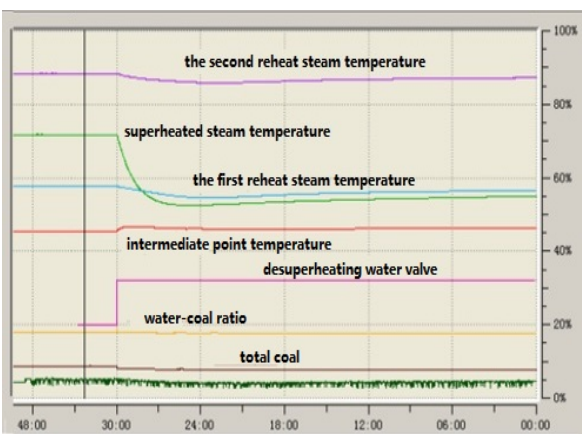

Fig.3. The second superheater desuperheating

water valve on the effects of steam temperature

Experiment 3 looks at how flue gas damper affects steam temperature. Flue gas damper adjusts mainly the deviation of the first and the second reheat steam temperature, the resistance of the flue is increased or decreased by changing two flue damper opening, so as to change the allocation proportion of flue gas in two flue, change flue gas heat in two flue, and thus achieve the goal of adjusting the steam temperature. One of the first and the second reheat flue gas damper opening proportion is selected as the input because that the sum of them is 1 . The paper takes a proportion of the first reheat flue gas damper opening as the input, the first reheat flue gas damper opening is $100 \%$ all the time, while the second reheat flue gas damper opening is decreased from $100 \%$ to $80 \%$. That is, the proportion of the first reheat flue gas damper opening is increased from 0.5 to 0.556 , and the proportion of the second reheat flue gas damper opening is decreased from 0.5 to 0.444 , the impact on the steam temperature is shown in Figure 4.

The transfer function is acquired between the proportion of the first reheat flue gas damper opening $\left(v_{3}\right)$ and the first reheat steam temperature $\left(y_{4}\right)$, the second reheat steam temperature $\left(y_{6}\right)$ as follows:

$$
G_{34}(s)=\frac{74.3092 e^{-22 s}}{(124.6970 s+1)^{2}}, \quad G_{36}(s)=\frac{93.2273}{(82 s+1)^{3}}-\frac{160.91}{(29 s+1)^{3}}
$$

Experiment 4 looks at how tilting angle of burner affects steam temperature. Tilting angle of burner adjusts mainly the overall average of the first and the second reheat steam temperature, temperature adjusting process is, in fact, that the reheat steam temperature is adjusted by changing the flame position to just the proportion of the heat distributed. For example, both reheat steam temperature will be increased as outlet flue gas temperature increases when tilting angle of burner looked a certain angle. Multi-layer swinging burner is used in this unit, tilting angle of burner 50\% stands for the horizontal position, $100 \%$ represents that tilting angle of burner is up by $30^{\circ}$, and $0 \%$ represents that tilting angle of burner is down by $30^{\circ}$. All the layers of the burner angle increase from $50 \%$ to $100 \%$ in the case of other conditions unchanged, the response of the steam temperature is obtained as shown in Figure 5.

The transfer function is acquired between tilting angle of burner $\left(v_{5}\right)$ and intermediate point temperature $\left(y_{1}\right)$, superheated steam temperature $\left(y_{2}\right)$, the first reheat steam temperature $\left(y_{4}\right)$, the 
second reheat steam temperature $\left(y_{6}\right)$ as follows:

$$
\begin{aligned}
& G_{51}(s)=\frac{0.135}{33.7 s+1}-\frac{0.164}{25.8 s+1}, \quad G_{52}(s)=\frac{-0.0769 e^{-89 s}}{707.4281 s+1} \\
& G_{54}(s)=\frac{0.0124}{(31.5738 s+1)^{2}}, \quad G_{56}(s)=\frac{0.0192}{(26.0647 s+1)^{2}}
\end{aligned}
$$

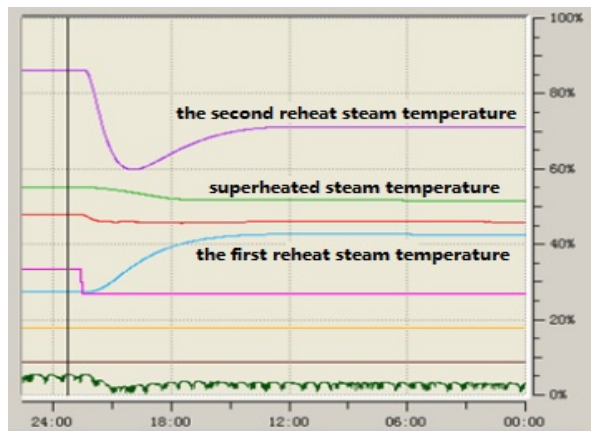

Fig.4. Flue gas damper on the effects of steam temperature

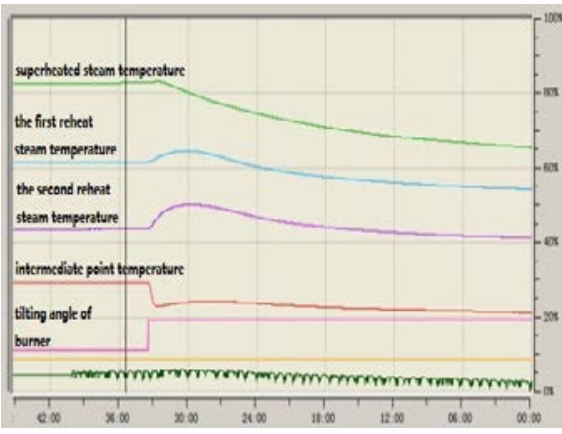

Fig.5. Tilting angle of burner on the effects of steam temperature

Experiment 5 looks at how desuperheating water valve affects the first and the second reheat steam temperature. The experiment that the first and the second reheat steam temperature respond to desuperheating water valve is carried out in the same method, the response obtained is shown in Figure 6, 7.

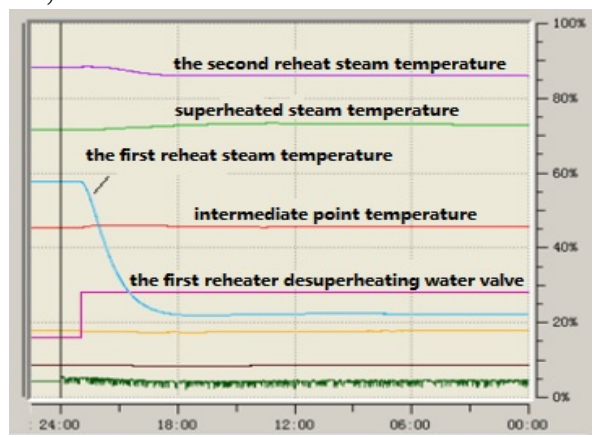

Fig.6. The first reheater desuperheating water valve between $40 \%$ and $70 \%$

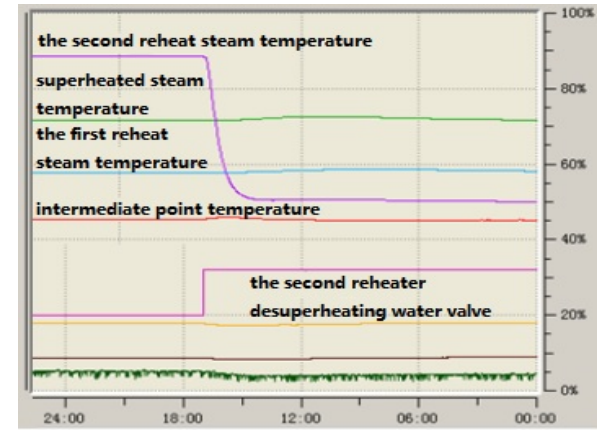

Fig.7. The second reheater desuperheating water valve between $40 \%$ and $70 \%$

Experiment data from Figure 6 are used to identify the system based on the standard PSO, the transfer function is acquired between the first reheater desuperheating water valve $\left(v_{4}\right)$ and the first reheat steam temperature $\left(y_{4}\right)$, the second reheat steam temperature $\left(y_{6}\right)$ as follows:

$$
G_{44}(s)=\frac{-0.3540}{(25.6160 s+1)^{3}}, G_{46}(s)=\frac{-0.0232}{(26.7027 s+1)^{5}}
$$

The transfer function is obtained between the second reheater desuperheating water valve $\left(v_{6}\right)$ and the second reheat steam temperature $\left(y_{6}\right)$ as follows:

$$
G_{66}(s)=\frac{-0.3809}{(19.5890 s+1)^{2}}
$$

\section{Simulink model of steam temperature system in double reheat ultra-supercritical unit}

The transfer functions that using the above six groups of experiment data to identify are built in Matlab/Simulink, the 6 input 6 output transfer function model of this steam temperature system is shown in Figure 8. 


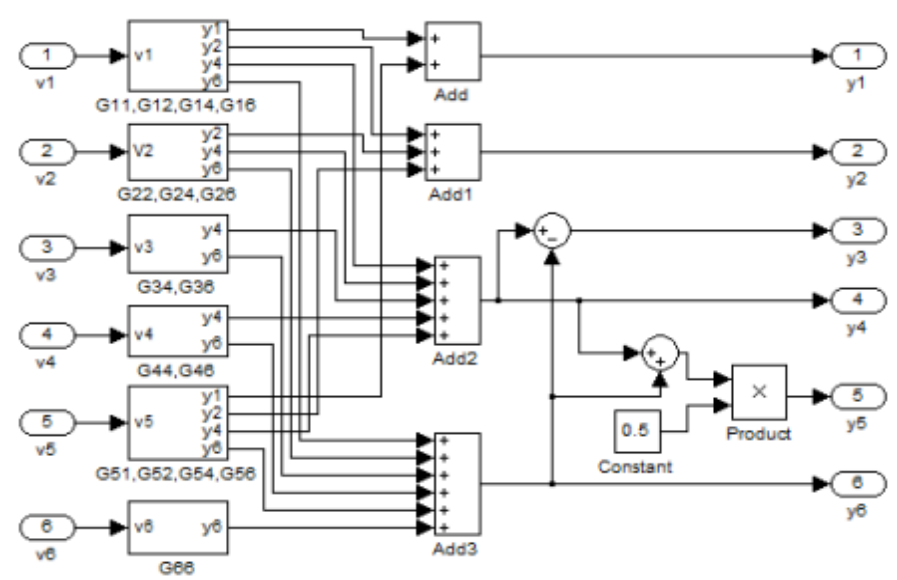

Fig.8. 6 input 6 output steam temperature system model

The comparison results between the measured data under various disturbances and the identification result are shown in Figure 9.
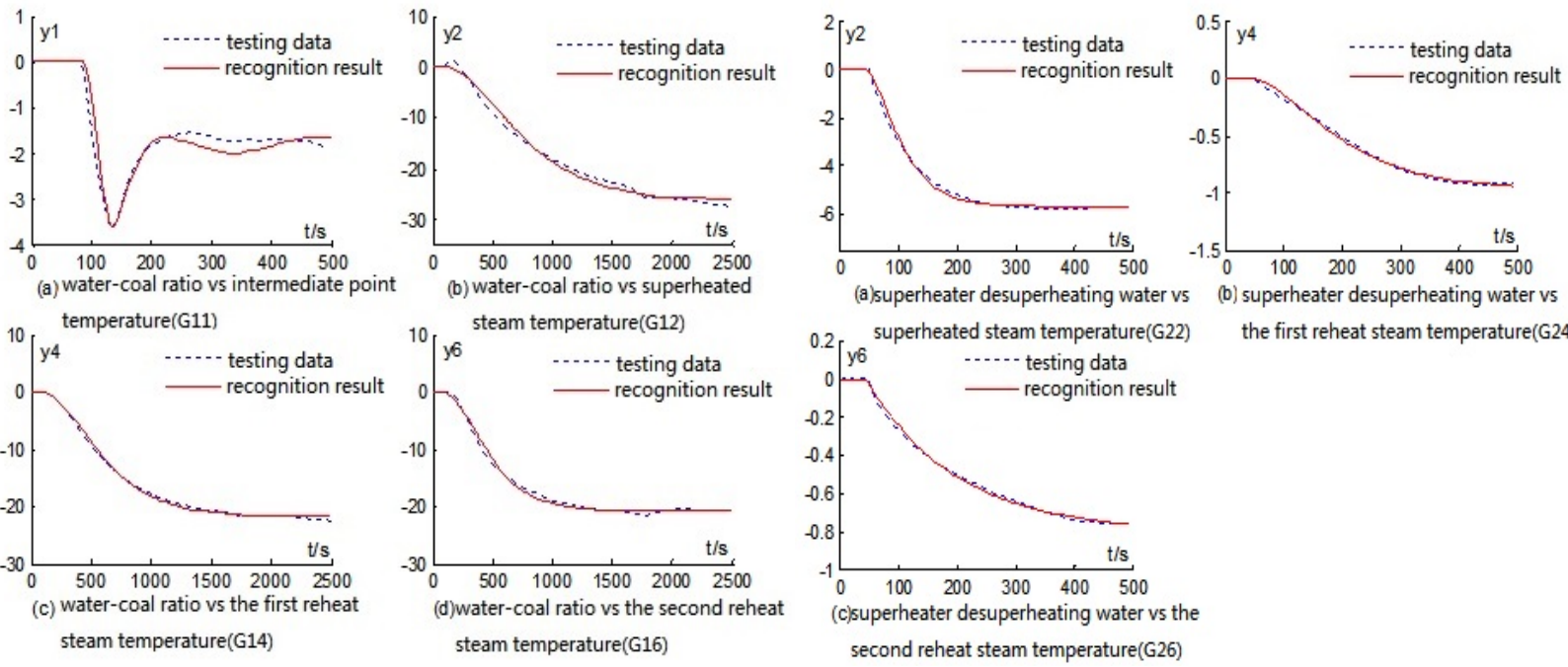

(a) Water-coal ratio disturbance
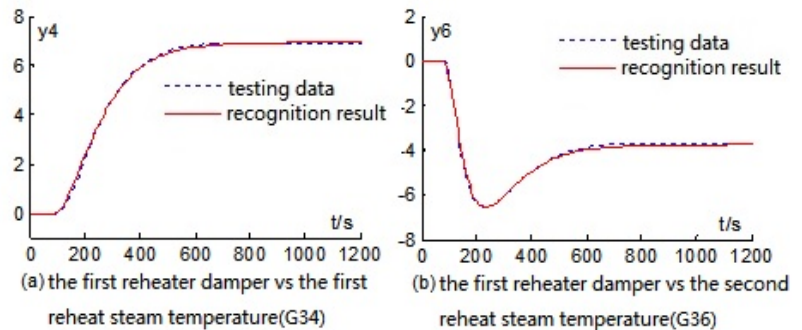

(c) Flue gas damper disturbance
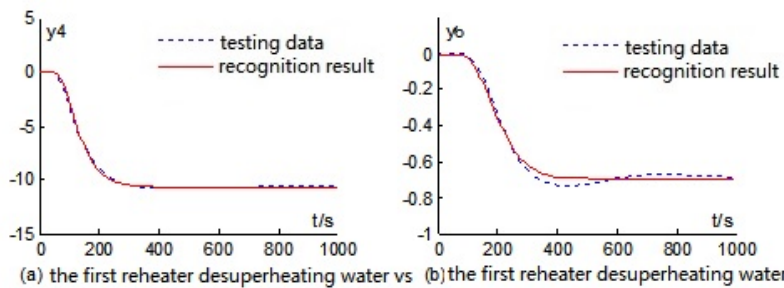

(e) The first reheater desuperheating water disturbance (b) Superheater desuperheating water disturbance
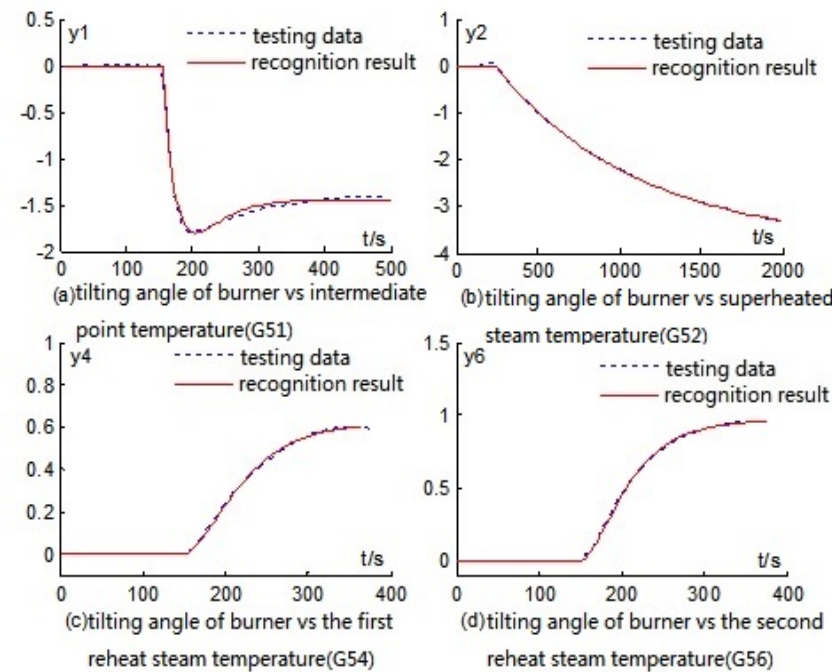

(d) Tilting angle of burner disturbance 


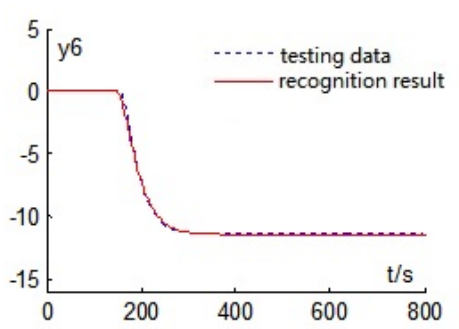

(f) The second reheater desuperheating water disturbance

Fig.9. The comparison results

Figure 9 shows that the recognition result coincides well with the testing curves, which indicates the higher accuracy of the recognition result. In the abstract, HP casing and the first reheater is between the superheated steam temperature and the first reheat steam temperature, HP casing and the second reheater separate the first reheat steam temperature from the second reheat steam temperature. Thus, inertia time $\mathrm{T}$ in $G_{12}(s), G_{14}(s)$, and $G_{16}(s)$ should have increased in turn, but the transfer function that using the experiment data to identify is not the case. In this analysis, the reason may be due to the influence that the first steam temperature and the second steam temperature is affected by steam disturbance is greater than the higher steam temperature changes, and may also be caused by inaccurate simulation model.

\section{Conclusion}

This paper analyzes the main influence factors of the superheated steam temperature, the first reheat steam temperature, and the second reheat steam temperature in double reheat ultra-supercritical unit, and determines the model structure. The output experiment data is obtained under various disturbances by carrying out disturbance experiment in the simulation system of 1000MW double reheat unit. The transfer function models are obtained by carrying out the standard PSO to identify model according to the test data. A complete model of the steam temperature system is built on Matlab/Simulink by using the above models. Simulation results indicate that the simulation model response carves under various disturbances are consistent with the experiment results, and show the accuracy of the model.

\section{References}

[1] Kennedy J. Particle Swarm Optimization[M]. Encyclopedia of Machine Learning. Springer US, 2010: 760-766.

[2] Qi Kang, Lei Wang, Derong Liu, et al. Parameter Approximate Dynamic Optimization for PSO Systems[C]. Decision and Control, 2009 held jointly with the 2009 28th Chinese Control Conference. CDC/CCC 2009. Proceedings of the 48th IEEE Conference on. IEEE, 2009: 5003-5008.

[3] Weixing Lin, Qiting Gu, Yanhai Chen. Multi-rate System Identification Based on Improved PSO[C]. Electronic Measurement \& Instruments, 2009. ICEMI'09. 9th International Conference on. IEEE, 2009: 3-616-3-620.

[4] Qun Jia, Yongxin Li. The Analysis and Application of the Monitor Model of Gasifier Temperature Based on the PSO Neural Network[C]. Instrumentation, Measurement, Computer, Communication and Control (IMCCC), 2013 Third International Conference on. IEEE, 2013: 335-338.

[5] Tianpei Zhou. Temperature Control Method for Water-coal-mixture Gasifier System Based on Fuzzy Control Rules Optimized by PSO Algorithm[C]. Measurement, Information and Control (ICMIC), 2013 International Conference on. IEEE, 2013, 2: 793-796. 